\title{
Validation of the 15 Minute Balke Field Test for Competitive, Adult 5K Runners: From Treadmill $\mathrm{VO}_{2 \max }$ Testing to Enhancing Performance
}

\author{
Ryan D. Mitchell*, Caitlyn Crandall \\ Nutrition Science, The Sage Colleges, Troy, NY, USA \\ *Corresponding author: mitchr2@sage.edu
}

\begin{abstract}
The purpose of this study was to determine the validity of a 15 minute field test of $\mathrm{VO}_{2 \max }$ in competitive adult male and female $5 \mathrm{k}$ runners and analyze the factors that contribute to the $\mathrm{VO}_{2 \max }$ of runners in the field versus on a treadmill. Nineteen trained, endurance runners completed a graded treadmill test and a 15 minute field test on a $400 \mathrm{~m}$ track (the Balke field test) to independently determine $\mathrm{VO}_{2 \max }$. We compared the data using a paired sample t-test, Pearson's correlation, and multiple linear regression. Treadmill $\mathrm{VO}_{2 \max }$ of runners was significantly higher than the $\mathrm{VO}_{2 \max }$ determined by the 15 minute field test $(56.9+/-5.3 \mathrm{ml} / \mathrm{min} / \mathrm{kg}$ vs. 52.7 $+/-4.3 \mathrm{ml} / \mathrm{min} / \mathrm{kg}, \mathrm{t}(18)=6.609, \mathrm{p}=000)$. We found a strong correlation when both treadmill pace at $\mathrm{VO}_{2 \max }$ and treadmill $\mathrm{VO}_{2 \max }$ were used as predictive factors for field $\mathrm{VO}_{2 \max }\left(\mathrm{r}^{2}=848, \mathrm{p}=.000\right)$ with treadmill pace at $\mathrm{VO}_{2 \max }$ having the strongest associative power in the correlation $(\beta=.636, p=001)$. The 15 minute field test is an adequate test of $5 \mathrm{~K}$ race readiness, with the addition of treadmill test giving athletes and coaches an assessment of race fitness relative to aerobic capacity. In addition to treadmill $\mathrm{VO}_{2 \max }$, coaches and athletes must consider additional performance factors such as treadmill pace at $\mathrm{VO}_{2 \max }$, lactate threshold, running economy, motivation, etc. for the prediction of field or performance $\mathrm{VO}_{2 \max }$.
\end{abstract}

Keywords: running, coaching, cardiopulmonary exercise test, Balke field test, treadmill test, mathematical model

Cite This Article: Ryan D. Mitchell, and Caitlyn Crandall, "Validation of the 15 Minute Balke Field Test for Competitive, Adult 5K Runners: From Treadmill $\mathrm{VO}_{2 \max }$ Testing to Enhancing Performance." American Journal of Sports Science and Medicine, vol. 5, no. 3 (2017): 44-47. doi: 10.12691/ajssm-5-3-1.

\section{Introduction}

We believe that assessing aerobic capacity is of great value for running coaches to establish the performance potential of their athletes in common events such as the $5 \mathrm{~K}$ through $15 \mathrm{~K}$. The gold standard for assessing aerobic capacity is the $\mathrm{VO}_{2 \max }$ test conducted in laboratory. [1,2] Due to a number of factors, however, runners are challenged to reach and sustain their full potential during competition. To determine the race readiness of their athletes, coaches would benefit from a reliable field test of race fitness that likewise demonstrates fitness relative to aerobic capacity.

$\mathrm{VO}_{2 \max }$ is expressive of cardiorespiratory fitness, endurance, performance, and aerobic capacity, with high $\mathrm{VO}_{2 \max }$ values associated with high levels of each. [3,4] Because of the high amount of information testing gives, researchers use $\mathrm{VO}_{2 \max }$ testing to understand the physiological aspects related to sports performance. [5] While $\mathrm{VO}_{2 \max }$ testing during a graded treadmill test proves to be exceptionally accurate, valid, and consistent, laboratory testing is time intensive, costly, equipment intensive, and requires specialized training. Because of these limitations, researchers have developed many alternative field tests to determine $\mathrm{VO}_{2 \max }$. The tests are generally easy to administer, less costly, take less time, and allow users to test multiple individuals at once. [6] Additionally, coaches can use field tests to evaluate an athlete or team's fitness before, during, or after a competitive season or change in training. [5]

As competitive $5 \mathrm{~K}$ runners operate at or near $\mathrm{VO}_{2 \max }$ for the duration of a $5 \mathrm{~K}$ race, duplicating such efforts requires testing that stresses runners to the maximum, and is of sufficient duration to replicate racing times of competitive runners. While researchers have evaluated 12 minute and 1.5 mile field tests, these tests do not begin to replicate the $5 \mathrm{~K}$ race distance nor finish times of competitive runners. $[7,8,9,10,11]$ The Balke field test (hereafter referred to as the 15 minute field test), however, is a 15 minute maximal effort running test (done on a 400 $\mathrm{m}$ track) that was developed by Bruno Balke in 1954 for testing $\mathrm{VO}_{2 \max }$ outside of the laboratory. [12] Balke established that since $\mathrm{VO}_{2 \max }$ testing measures the aerobic work capacity, the duration of physiologically meaningful tests should be at least 12 minutes in duration, yet not so long as to introduce fatigue and reduced motivation as compounding factors. Balke also established a relationship between running velocities and oxygen requirement in which oxygen requirements between $133 \mathrm{~m} / \mathrm{min}$ (5 mph) and $290 \mathrm{~m} / \mathrm{min}$ (11 $\mathrm{mph}$ ) were found to be linearly related to running performance. In testing completed on high school boys, Balke demonstrated that the $\mathrm{VO}_{2 \max }$ determined from field test data correlated well with 
treadmill test in the laboratory, yet there has not been much research on the 15 minute field test since then, particularly in trained, adult competitive runners. [12]

We seek to fill in the gaps regarding research utilizing the 15 minute field test by comparing a maximal $\mathrm{VO}_{2 \max }$ treadmill test in the laboratory on a group of trained, adult male and female runners to the 15 minute field test. In particular, we seek to determine the correlation between the $\mathrm{VO}_{2 \max }$ of these tests and to analyze the factors that contribute to $\mathrm{VO}_{2 \max }$ in the field (hereafter referred to as field $\mathrm{VO}_{2 \max }$ ) versus $\mathrm{VO}_{2 \max }$ determined on the treadmill (hereafter called treadmill $\mathrm{VO}_{2 \max }$ ). A validated test would provide a means for coaches to determine the race readiness of their athletes outside of the confines of a race, and allow coaches to assess fitness relative to the aerobic capacity of their runners. Finally, based on what is known and determined here about the factors that contribute to a runners $\mathrm{VO}_{2 \max }$, we propose a regression model for the prediction of field $\mathrm{VO}_{2 \max }$. As reviewed and further refined by George, et al., regression models to predict $\mathrm{VO}_{2 \max }$ are not without precedent given their extensive use by researchers in extrapolating $\mathrm{VO}_{2 \max }$ from exercise data [13].

\section{Materials and Methods}

A total of nineteen subjects consisting of males $(n=9)$ and females $(n=10)$ between 23 and 49 years of age (mean age of 32 years) considered physically active, trained runners participated in this study. All participants were familiar with both treadmill and track running. We determined medical clearance for subject participation based on criterion of the American Heart Association (AHA) and American College of Sports Medicine (ACSM). We obtained Institutional Review Board (IRB) approval for the study from The Sage Colleges IRB committee.

For treadmill (Trackmaster TMX-425CP Treadmill) testing, we maintained the laboratory at $\sim 70^{\circ} \mathrm{F}$ and $50 \%$ humidity, and used a fan to cool runners during testing. We fit each subject with a COSMED heart rate monitor strap, and instructed each to warm up for ten minutes on the treadmill at a slope of 0 degrees at a comfortable pace. While the subject was warming up, we calibrated a COSMED Quark CPET to facilitate accurate $\mathrm{VO}_{2 \max }$ determination. After the runner's warm up and CPET calibration, we fit runners with a COSMED exercise mask. During the tests, we maintained the treadmill at a constant grade of $2 \%$ while we increased pace from a typical warm up pace by $1 \mathrm{~km} / \mathrm{hr}$ per minute until the runner reached voluntary exhaustion, or three of the criterion for $\mathrm{VO}_{2 \max }$ had been met: RER $\left(\mathrm{vCO}_{2} / \mathrm{vO}_{2}\right)$ greater than or equal 1.10 , heart rate greater than $95 \%$ of age predicted maximum, and plateau of volume of oxygen inhaled $\left(\mathrm{VO}_{2}\right)$. We considered a plateau in $\mathrm{VO}_{2}$ when the $\mathrm{VO}_{2}$ value did not change more than $2 \mathrm{ml} / \mathrm{min} / \mathrm{kg}$ over the course of a minute.
For analysis of $\mathrm{VO}_{2 \max }$, we used 15 second averaging of the CPET raw data. We determined $\mathrm{VO}_{2 \max }$ by averaging four consecutive data points at the plateau of each runner's data.

After all participants completed the graded treadmill run in the laboratory, we conducted the 15 minute field test on a standard 400-meter running track. We completed the test within two and half weeks of treadmill testing to minimize any effects of training on $\mathrm{VO}_{2 \max }$ since all participants trained regularly. The day of the test the temperature was $50^{\circ} \mathrm{F}$, humidity $32 \%$, with an $8 \mathrm{mph}$ wind. All participants ran the test on the track together. We gave participants a brief overview of the test including instructions to run as fast as they can when told "GO" at the beginning of the test, weighed each runner before the test, and assigned bib trackers to facilitate automatic Chronotrack timing. We then instructed participants to warm up 10 minutes prior to beginning the 15 minute field test. To make sure runners could keep track of their time during the run, we placed a large racing clock near the start line. The number of laps completed during the 15 minute period was automatically counted by the Chronotrack system. At the end of the 15 minute period, we instructed runners to stop where they were on the track. We measured the distance each runner proceeded past the 400-meter mark of their last lap with a measuring wheel, and computed $\mathrm{VO}_{2 \max }$ using the formula, $\mathrm{VO}_{2 \max }=$ $((($ Total distance covered $\div 15$ minutes $)-150) \times 0.178)+$ 33.3. The base constant value of 150 represents the first 150 meters per minute of running during which energy is considered to be derived primarily from anaerobic metabolism and thus has little correlation with a runner's aerobic capacity. The 0.178 multiplier is used to associate the aerobic contribution in milliliters of oxygen per kilogram of body mass per minute for each meter run beyond the first 150 meters per minute. The value 33.3 represents the $\mathrm{VO}_{2}$ of $33.3 \mathrm{ml} / \mathrm{kg} / \mathrm{min}$ for the first $150 \mathrm{~m}$ [14].

We determined the correlation between treadmill $\mathrm{VO}_{2 \max }$ and field $\mathrm{VO}_{2 \max }$ using Pearson's correlation, and analyzed for differences between the treadmill $\mathrm{VO}_{2 \max }$ and field $\mathrm{VO}_{2 \max }$ values with a two-tailed paired t-test. We used regression analysis to determine the dependence of field $\mathrm{VO}_{2 \max }$ values on treadmill $\mathrm{VO}_{2 \max }$ values, and to analyze the dependence of field $\mathrm{VO}_{2 \max }$ values on both treadmill $\mathrm{VO}_{2 \max }$ and the pace at which treadmill $\mathrm{VO}_{2 \max }$ was reached. We considered statistical significance for $\mathrm{p}$ values less than 0.05 ( $\mathrm{p}<0.05)$.

No conflicts of interest existed that could have inappropriately influenced the study.

\section{Results}

Mean treadmill $\mathrm{VO}_{2 \max }$ for runners was significantly higher than their mean field $\mathrm{VO}_{2 \max }$ (Table 1).

Table 1. Mean (and Standard Deviation) of $\mathrm{VO}_{2 \max }$

\begin{tabular}{|c|c|c|c|c|}
\hline Treadmill Test & 15-Minute Field Test & t-statistic & df \\
\hline $56.9+/-5.3 \mathrm{ml} / \mathrm{min} / \mathrm{kg}$ & $52.7+/-4.3 \mathrm{ml} / \mathrm{min} / \mathrm{kg}^{*}$ & 6.069 & 18 & .000 \\
\hline
\end{tabular}

${ }^{*}$ For an $\mathrm{N}$ of 19 , data are statistically significant to $\mathrm{p}<.001$ in the Paired samples t-test; analyzed using IBM SPSS v.24. 
Table 2. Regression Analysis: Predictors of Field $\mathrm{VO}_{2 \max }$

\begin{tabular}{|c|c|c|c|c|}
\hline & $\mathrm{R}$ & $\mathrm{R}$ Square & F Change & Significance (2-tailed) \\
\hline Treadmill $\mathrm{VO}_{2 \max }$ & 0.828 & 0.686 & & 0.000 \\
\hline Treadmill pace at $\mathrm{VO}_{2 \max }$ and Treadmill $\mathrm{VO}_{2 \max }$ & 0.921 & 0.848 & 44.487 & 0.000 \\
\hline
\end{tabular}

For an $\mathrm{N}$ of 19 , the data are statistically significant to $\mathrm{p}<.001$ in the Pearson's correlation coefficient, R. Significance for the prediction of field $\mathrm{VO}_{2 \max }$ using both treadmill pace at $\mathrm{VO}_{2 \max }$ and the treadmill $\mathrm{VO}_{2 \max }$ as predictors was determined using the $\mathrm{F}$-test.

Runners $\mathrm{VO}_{2 \max }$ values from the treadmill and field tests were significantly correlated as determined by Pearson's correlation coefficient, R (Table 2). This correlation, however, suggests that only $69 \%$ of the variability in the field $\mathrm{VO}_{2 \max }$ values can be explained by the treadmill $\mathrm{VO}_{2 \max }$ values. Results from multiple linear regression showed that including the pace at which treadmill $\mathrm{VO}_{2 \max }$ was reached along with the treadmill $\mathrm{VO}_{2 \max }$ value resulted in better explanatory power for field $\mathrm{VO}_{2 \max }$ compared to simply the treadmill $\mathrm{VO}_{2 \max }$ value alone, suggesting that $85 \%$ of variability in the field $\mathrm{VO}_{2 \max }$ values can be explained by the combination of treadmill $\mathrm{VO}_{2 \max }$ values and the pace at which treadmill $\mathrm{VO}_{2 \max }$ was reached (see Table 2).

Furthermore, the standardized $\beta$-coefficient from the regression analysis indicates that treadmill pace at $\mathrm{VO}_{2 \max }$ is associated with $64 \%$ of the correlation between the treadmill and field tests (Table 3).

Table 3. Prediction of Field $\mathrm{VO}_{2 \max }$ Using Both Treadmill Pace at $\mathrm{VO}_{2 \max }$ and Treadmill $\mathrm{VO}_{2 \max }$ as Predictors

\begin{tabular}{|l|c|c|}
\hline & Standardized $\beta$-Coefficients & Significance \\
\hline Treadmill $\mathrm{VO}_{2 \max }$ & 0.334 & .000 \\
\hline Treadmill pace at $\mathrm{VO}_{2 \max }$ & 0.636 & .001 \\
\hline
\end{tabular}

\section{Discussion}

Field testing is a more practical and readily available method of assessing $\mathrm{VO}_{2 \max }$ as compared to treadmill testing in the laboratory for a variety of reasons. [1,4] In this study of adult female and male trained runners, the correlation (albeit lower) between treadmill $\mathrm{VO}_{2 \max }$ and field $\mathrm{VO}_{2 \max }$ is consistent with what Balke reported for testing in boys. [12] Our result is also consistent with the high correlations researchers found between treadmill tests and other maximal field test studies completed on physically active males utilizing either 12 minute run tests completed on a flat surface [7] or indoor track [11], and a test utilizing a 1.5 mile run conducted on adult males and females. [15] The lower correlation we observed is likely due to having trained runners of varying levels of race fitness and ability, and the wide age range of subjects in this study. However, we believe that the higher correlation of field $\mathrm{VO}_{2 \max }$ as predicted by the combination of treadmill pace at $\mathrm{VO}_{2 \max }$ and treadmill $\mathrm{VO}_{2 \max }$, along with the strong association of treadmill pace at $\mathrm{VO}_{2 \max }$ with field $\mathrm{VO}_{2 \max }$ identified here is particularly useful for helping to explain why many of the runners in this study with similar treadmill $\mathrm{VO}_{2 \max }$ displayed very different field $\mathrm{VO}_{2 \max }$ results; they're treadmill pace at $\mathrm{VO}_{2 \max }$ was different.

In this study, we found significantly higher treadmill $\mathrm{VO}_{2 \max }$ values in comparison to the $\mathrm{VO}_{2 \max }$ values determined by the 15 minute field test on the track. In a study conducted by Meyer et al., researchers did not find significant differences between track and treadmill $\mathrm{VO}_{2 \max }$ values, yet, they did find higher submaximal $\mathrm{VO}_{2}$ values on the treadmill. [16] The consistently lower field $\mathrm{VO}_{2 \max }$ values for runners found in our study may be related to the fact that treadmill testing only requires runners to be at maximal effort for a brief period of time, thus limiting the cumulative effects of performance factors such as motivation, pain tolerance, psychological makeup, and running economy. $[17,18]$ Unless runners have mastered these factors, these have the effect of limiting the extent to which one can run to their lab tested, treadmill $\mathrm{VO}_{2 \max }$ during a competitive event of significant duration such as a $5 \mathrm{~K}$. On the other hand, competitive runners may find it useful to work toward their $\mathrm{VO}_{2 \max }$ determined aerobic capacity to make the most of their aerobic engine.

Our data suggests that while treadmill $\mathrm{VO}_{2 \max }$ measurements correlate with the 15 minute field test of $\mathrm{VO}_{2 \max }$, treadmill $\mathrm{VO}_{2 \max }$ is not sufficient for coaches to predict field $\mathrm{VO}_{2 \max }$ nor should treadmill $\mathrm{VO}_{2 \max }$ data alone be used to set up training recommendations for $5 \mathrm{~K}$ runners. On the other hand, we believe that coaches could use data from the combination of treadmill $\mathrm{VO}_{2 \max }$ testing and 15 minute field tests to determine training recommendations. We believe that the field $\mathrm{VO}_{2 \max }$ is analogous to the runner's performance $\mathrm{VO}_{2 \max }$ ("VDOT") giving a test of race readiness outside of the confines of a race, and gives an assessment of fitness relative to the aerobic capacity of runners. VDOT was developed by Jack Daniels and represents the amount of oxygen consumed per minute by an athlete determined by race performances, or performance in regard to time to run a specific distance. [17,18] Daniels described that performance $\mathrm{VO}_{2 \max }$ data encompasses many factors such as motivation, lactate threshold, pain tolerance, psychological makeup, and running economy. Thus, we believe that coaches and therapists could assist runners in working toward their laboratory determined aerobic capacity by making concerted efforts to understand and control the contribution that each of the factors have on their performance.

Although we found that 15 minute field test and the treadmill determined $\mathrm{VO}_{2 \max }$ values are strongly correlated and the mean difference in $\mathrm{VO}_{2 \max }$ is significant in trained adult male and female runners, a meaningful \% difference cannot be applied to a runners' treadmill $\mathrm{VO}_{2 \max }$ to calculate their field $\mathrm{VO}_{2 \max }$ given the inconsistent nature of the individual differences amongst runners. In the future, however, additional research may allow coaches to estimate field $\mathrm{VO}_{2 \max }$ and thus $5 \mathrm{~K}$ performance based on factors identified by Daniels and others, and as highlighted here. In this study, regression analysis indicated that only $85 \%$ of the variability in the field $\mathrm{VO}_{2 \max }$ of runners is due to treadmill pace at $\mathrm{VO}_{2 \max }$ and treadmill $\mathrm{VO}_{2 \max }$, suggesting that other factors must be 
present. And, $64 \%$ of this variability is associated with treadmill pace at $\mathrm{VO}_{2 \max } ; 33 \%$ associated with treadmill $\mathrm{VO}_{2 \max }$. Thus, a regression model of field or performance $\mathrm{VO}_{2 \max }$ for an individual runner begins to take shape in which their unique performance $\mathrm{VO}_{2 \max }=\left(\beta_{\text {weight }} \mathrm{x}\right.$ treadmill pace at $\left.\mathrm{VO}_{2 \max }\right)+\left(\beta_{\text {weight }} \mathrm{x}\right.$ treadmill $\left.\mathrm{VO}_{2 \max }\right)+$ $\left(\beta_{\text {weight }} \mathrm{x}\right.$ lactate threshold $)+\left(\beta_{\text {weight }} \mathrm{x}\right.$ running economy $)+$ ( $\beta_{\text {weight }} \times$ psychological factors $)+\left(\beta_{\text {weight }} \mathrm{x}\right.$ tolerance to environmental challenges (heat and humidity)). $\quad \beta_{\text {weight }}$ represents standard multiple regression coefficients thus requiring researchers to apply multiple linear regression and a stepwise model selection tool to determine the unique contribution and significance that each of these factors have toward predicting field $\mathrm{VO}_{2 \max }$ of a runner. [13] In a regression model for prediction of $\mathrm{VO}_{2 \max }$ from exercise and non-exercise data, George et al. incorporated questionnaire data for perceived functional ability (PFA) and a physical activity rating (PA-R) to generate meaningful coefficients, in which PFA may account for factors such as lactate threshold and running economy. [13,19] Thus, in the model proposed here, PFA may provide a reasonable solution to gauging lactate threshold (also measureable directly in the laboratory) and running economy. Similarly, a questionnaire may provide a suitable approach for researchers to determine the contribution that motivation/psychological factors and tolerance to environmental challenges have on the proposed regression model.

\section{Conclusion}

In this study, we determined that the field $\mathrm{VO}_{2 \max }$ of trained, adult $5 \mathrm{~K}$ runners is strongly correlated with their treadmill $\mathrm{VO}_{2 \max }$ with treadmill pace at $\mathrm{VO}_{2 \max }$ having the greatest explanatory power in the correlation. These data help to inform coaches why runners of the same $\mathrm{VO}_{2 \max }$ determined in the laboratory do not run to the same $\mathrm{VO}_{2 \max }$ in a 15 minute field test on the track. The 15 minute field test can be used by coaches to determine training recommendations and to assess the race fitness of runners relative to their aerobic capacity. Due to individual differences between runners in the relationship between $\mathrm{VO}_{2 \max }$ determined by treadmill and field testing, it is not possible to extrapolate field or performance $\mathrm{VO}_{2 \max }$ from laboratory data alone. This will require knowledge of the relationships between multiple performance factors for each runner.

\section{Acknowledgements}

The authors wish to thank Dick Vincent for sharing his technical expertise in the training and assessment of runners. Dick Vincent is a Level 3 USATF Certified Coach and a Level 5 IAAF Certified Elite Endurance Coach. We appreciate the contributions of Dr. Julie Lindenbaum to deepening our understanding of the statistics used in this study. Dr. Lindenbaum is a lecturer in the Psychology Department at The Sage Colleges. The authors would like to thank Albany Running Exchange Event Productions for assisting with timing of the 15 minute track test, and thank the runners from the Albany Running Exchange who participated in the treadmill and track tests.

\section{References}

[1] Burke, E.J. "Validity of selected lab and field tests of physical working capacity”, U.S. Dept of Health, ERIC Number: ED100839, 1976.

[2] Vickers, R.R., "Measurement error in maximal oxygen uptake tests”, Naval Health Research Center, Report No. 04-03, 2003.

[3] Ramsbottom, R., Brewer, J., and Williams, C., "A progressive shuttle run test to estimate maximal oxygen uptake", British Journal of Sports Medicine, 32. 141-144. 1988.

[4] Billat, V.L., Hill, D.W., Pinoteau, J., Petit, B., and Koralsztein, J.P., "Effect of protocol on determination of velocity at $\mathrm{VO}_{2 \max }$ and on its time to exhaustion", Archives of Physiology and Biochemistry, 104. 313-321. 1996.

[5] Nieman, D. Exercise testing and prescription: Cardiorespiratory fitnesss, McGraw-Hill, New York, NY, 2011.

[6] Larsen, G.E., George, J.D., Alexander, J.L., Fellingham, G.W., Aldana, S.G., and Parcell, A.C., "Prediction of maximum oxygen consumption from walking, jogging, or running”, Research Quarterly for Exercise and Sport, 73. 66-72. 2002.

[7] Cooper, K., “A means of assessing maximal oxygen intake: correlation between field and treadmill testing", Journal of the American Medical Association, 203(3). 201-204. 1968.

[8] Getchell, L.H., Kirkendall, D., and Robins, G., Prediction of maximal oxygen uptake in young adult women joggers. Research Quarterly, 48. 61-67. 1977.

[9] Jackson, A., Dishman, R.K., La Crox, S., Patton, R., and Weinberg, R., "The heart rate, perceived exertion, and pace of the 1.5 mile run”, Medicine and Science in Sports and Exercise, 13(4). 224-228. 1981.

[10] Anderson, G.S. "A comparison of predictive tests of aerobic capacity”, Canadian Journal of Sports Science, 17(4). 304-308. 1992.

[11] Grant, S., Corbett, K., Amjad, A.M., Wilson, J., and Aitchison, T., "A comparison of methods of predicting maximum oxygen uptake”, British Journal of Sports Medicine, 29. 147-152. 1995.

[12] Balke, B., "A simple field test for the assessment of physical fitness”, Civil Aeromedical Research Institute, 63. 1-8. 1963.

[13] George, J.D., Paul, S.L., Hyde, S.L., Bradshaw, D.I., Vehrs, P.R., Hager, R.L., and Yanowitz, F.G., "Prediction of maximum oxygen uptake using both exercise and non-exercise data”, Measurement in Physical Education and Exercise Science, 13(1). 1-12. 2009.

[14] Vigel, J.I., Road to the top: A systematic approach to distance training that produced one of America's greatest running programs, Creative Designs, Inc., Albuquerque, New Mexico, 1995.

[15] Jackson, B.K., "A comparison of completion times between a 1.5-mile run on an indoor track and treadmill in physically active individuals”, [Master's thesis], Oklahoma: University of Central Oklahoma, 2008.

[16] Meyer, T., Welter, J.P., Scharhag, J., and Kindermann, W., "Maximal oxygen uptake during field running does not exceed that measured during treadmill exercise”, European Journal of Applied Physiology, 88(4). 387-389. 2003.

[17] Daniels D. “Threshold training: finding your VDOT”, Runners World, December 2005. Available:

http://www.runnersworld.com/workouts/threshold-trainingfinding-your-vdot\#. [Accessed Sept. 26, 2016].

[18] Strout, E., “A Running Life: Jack Daniels”, Runners World, April 6, 2015.

http://www.runnersworld.com/runners-stories/a-running-life-jackdaniels. [Accessed Sept. 26, 2016].

[19] Bassett, D.R. and Howley, E.T., "Limiting factors for maximum oxygen uptake and determinants of endurance performance", Medicine and Science in Sports and Exercise, 32. 70-84. 2000. 